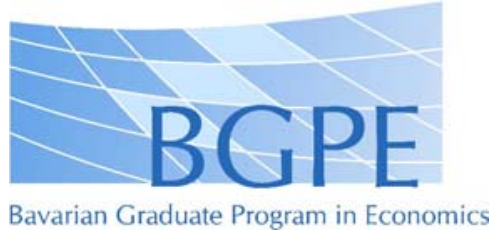

BGPE Discussion Paper

No. 12

\title{
Tax-Favored Retirement Accounts: Are they Efficient in Increasing Savings and Growth?
}

\author{
Hans Fehr \\ Christian Habermann \\ Fabian Kindermann
}

July 2006

ISSN 1863-5733

Editor: Prof. Regina T. Riphahn, Ph.D.

Friedrich-Alexander-University Erlangen-Nuremberg

(c) Hans Fehr, Christian Habermann, Fabian Kindermann 


\title{
Tax-Favored Retirement Accounts: Are they Efficient in Increasing Savings and Growth?*
}

\author{
Hans Fehr, Christian Habermann and Fabian Kindermann ${ }^{\ddagger}$
}

July 2006

\begin{abstract}
The present paper aims to quantify the macroeconomic and welfare effects of taxfavored retirement accounts. Starting from an equilibrium without saving incentives, we introduce such accounts and compute the new transition path and the resulting long-run equilibrium. Since our overlapping-generations model comprises a detailed progressive tax system, borrowing constraints as well as stochastic income risk, we can compare macroeconomic and liquidity effects, tax distortions and the insurance properties of the policy reform.

Our simulations indicate that tax-favored retirement accounts as implemented in many OECD countries will have a significant impact on capital accumulation and wage growth in the long run, but only yield insignificant aggregate efficiency changes. While elderly generations are typically hurt by such a reform, young and future generations benefit. Finally, with respect to the intragenerational redistribution, a subsidy system that includes direct bonus payments might be preferred to a system with pure tax deductions.
\end{abstract}

JEL Classification: H55, J26

Keywords: Savings incentives, stochastic general equilibrium model

*Financial support from the Forschungsnetzwerk Alterssicherung (FNA) of the Deutsche Rentenversicherung Bund is gratefully acknowledged.

‡ Department of Economics, University of Wuerzburg, Sanderring 2, D-97070 Würzburg Fax: ++49-931-888-7129, E-Mail: hans.fehr@mail.uni-wuerzburg.de 


\section{Motivation}

Like many other countries in the past, Germany has recently introduced individual retirement accounts (IRAs, popularly referred to as "Riester accounts" after the former labor minister Walter Riester) in order to compensate individuals for the future decline in public pensions. Income that is saved in these accounts is given a tax relief, the accumulation during the saving phase is tax exempt and qualified withdrawals are taxed as normal income.

In principle, German IRAs work similar as the respective accounts in the US or in Britain, but there are also some important differences with respect to the government regulation and the provided saving incentives ${ }^{1}$. Since the incentives are especially designed for low income households, they can take two forms: direct bonus payments which depend on the household characteristics (number of children, non-entitled partners) and tax deductions as special expenses. While the former are usually more advantageous for low income households, the latter will be chosen by higher income earners. In order to qualify for the maximum bonus payment, the beneficiary must invest a specified percentage of his gross earnings, otherwise the transfer payment is reduced accordingly. With respect to the tax deductions there exists an annual contribution ceiling which will be finally fixed at 2.100 $€$ and in the case of early withdrawal (i.e. before age 60 ) the accumulated previous tax savings and government subsidies have to be reimbursed to the tax authorities. Finally, approved payment plans must provide a life annuity after retirement.

The present paper aims to provide a comprehensive economic assessment of such savings subsidies. Since in Germany the take-up rate for IRAs was quite disappointing initially and only increased recently, it is important to isolate the policy instruments which are successful in boosting private savings. But the amount of contributions to IRAs alone is only a weak indicator for the policy effectiveness. With respect to the savings performance it is crucial whether contributions are funded from additional savings or diverted from other saving. In order to evaluate the distributional impact, it is important to know how the tax incentives benefit workers from different income levels and cohorts. It is also necessary to quantify the current and future budgetary implications in order to assess the implied tax distortions. Finally, in an uncertain environment we need to know how the reform alters the risk allocation across and within generations in order to judge its insurance effects.

While tax-favored retirement accounts were already introduced two decades ago in the US,

\footnotetext{
${ }^{1} \mathrm{~A}$ more detailed description of the German IRAs and a comparison of tax-favored retirement saving plans in OECD countries can be found in OECD (2005).
} 
there is still an ongoing discussion about their economic performance. At least partly this controversy is due to the limited data availability and the problems with the econometric specification, see Bernheim (2002) for a survey and discussion of this literature. For this reason we simulate the introduction of tax-favored retirement accounts with a numerical simulation model. This approach allows to isolate and compare the resulting individual reactions and macroeconomic consequences as well as to evaluate the welfare and efficiency implications of such reforms.

Already Engen et al. (1994) have examined the effectiveness of individual retirement accounts in the US. Applying a partial equilibrium life-cycle model, they compute the optimal individual saving behavior for alternative contribution limits and withdrawal rates. Their simulations indicate that individuals will mainly substitute from liquid savings in the short run and increase their aggregate savings only slightly in the long run. The present study applies a general equilibrium model which was pioneered by Auerbach and Kotlikoff (1987) and has been recently extended to include idiosyncratic income risk ${ }^{2}$. Imrohoroğlu et al. (1998) evaluate in this framework the long-run consequences of IRAs on the US capital stock for various contribution limits and tax savings instruments. They conclude that about 9 percent of IRA contributions during the 80ies constituted additional savings which raised the US capital stock by about 6 percent.

While İmrohoroğlu et al. (1998) do not provide a welfare analysis, applications such as Huang et al. (1997), De Nardi et al. (1999) or Conesa and Krueger (1999) evaluate the long run effects and the transition path when the current US pension system is either replaced by a two-tier system of personal saving accounts or completely eliminated. While these studies are able to compare the intergenerational welfare consequences of the considered reforms, they did not compute the aggregate efficiency gains or losses, which is required for an an overall assessment. Consequently, our study follows Nishiyama and Smetters (2005) as well as Fehr and Habermann (2005) who isolate the insurance and distortionary effects of the considered policy reforms by compensating agents along the transition path with lump-sum transfers or taxes. Compared to the original study of İmrohoroğlu et al. (1998), our approach also includes a richer structure of individual preferences as well as a progressive tax and subsidy system.

We find that a reform with unlimited tax deductions where the tax shortfalls are financed by consumption taxes and public debt yields the strongest growth effects and aggregate efficiency gains while the implied welfare losses for middle-aged current generations are only modest. However, such a reform is politically not feasible, since public debt rises

\footnotetext{
${ }^{2}$ For a recent survey of this literature, see De Nardi et al. (2001).
} 
dramatically. Consequently, tax-favored accounts in OECD countries are combined with limited saving subsidies in order to dampen the initial shortfalls in tax revenues. Our simulations indicate that such reforms still have a significant impact on capital accumulation in the long run. Depending on the applied policy mix, the latter will rise between 3.5 and 9.6 percent while between 11 and 14 percent of IRA contributions are additional savings. Despite the positive effects on capital accumulation, the aggregate efficiency gain is almost insignificant for most realistic parameter combinations. This is due to the fact that lower tax distortions have to be weighted against the reduced insurance properties of the tax system. With respect to the distributional consequences we find that the reform will reduce the welfare of elderly generations and increase the welfare of future generations by roughly 1 percent of their respective remaining lifetime resources. Finally, with respect to the specific saving incentives our simulations indicate that a mixture of tax deductions and bonuses as applied in Germany may be preferred due to the positive growth, distributional and efficiency consequences.

In the next section, we describe how we model the tax and benefit system and sketch the structure of the simulation model. Section 3 explains the calibration and simulation approach. Finally, section 4 presents the simulation results and section 5 offers some concluding remarks.

\section{The model economy}

\section{$2.1 \quad$ Preliminaries}

We consider an economy populated by overlapping generations of individuals which face random survival up to a maximum possible lifespan of $J=16$ periods, i.e. each model period covers five years. In addition to lifespan uncertainty, individuals also face productivity shocks during their working time. Labor supply is variable, but consumers are forced to retire at the retirement age $j_{R}=9$ (i.e. real age 60). During retirement, pensioners receive payroll-financed social security benefits and run down their accumulated assets. Apart from the pension system, the government levies a progressive personal tax on income from labor, capital and pensions as well as proportional taxes on consumption and corporate profits. Tax revenues are used to finance public goods and the interest payments on public debt. The production sector comprises a constant returns to scale Cobb-Douglas production function without technological progress and no aggregate uncertainty.

The initial equilibrium of our model economy is a steady state. Then the policy reform is 
implemented before the individual productivity of the next period is revealed, and a new equilibrium path in the closed economy is calculated. We assume zero population growth and keep the survival probabilities constant at initial values. Consequently, all agents face a probability $s_{j}$ of surviving up to age $j$, conditional of surviving up to age $j-1$. Every age $j$ cohort $N_{j}$ is fragmented into subgroups $\xi\left(z_{j}\right) N_{j}$ where $\sum_{z_{j}} \xi\left(z_{j}\right)=1$ reflecting their

state $z_{j}$ at a specific age $j$. The state $z_{j}=\left(j, e p_{j}, \mathrm{a}_{j}^{R}, \mathrm{a}_{j}, e_{j}\right)$ of an age $j$ agent describes the agent's earning points for public pension claims $e p_{j}$, tax-favored assets $\mathrm{a}_{j}^{R}$, ordinary asset holdings $\mathrm{a}_{j}$, and individual productivity $e_{j}$. In the following, we concentrate on the long run equilibrium and omit the state index $z_{j}$ for every variable whenever possible. Agents are then only distinguished according to their age $j$.

\subsection{The individual decision problem}

Our model assumes a preference structure that is represented by a time-separable, nested CES utility function. In order to isolate risk aversion from intertemporal substitution, we follow the approach of Epstein and Zin (1991) and formulate the maximization problem of a representative consumer at age $j$ and state $z_{j}$ recursively as

$$
V\left(z_{j}\right)=\max _{\ell_{j}, c_{j}}\left\{u\left(c_{j}, \ell_{j}\right)^{1-\frac{1}{\gamma}}+\frac{s_{j+1}}{1+\theta}\left[\sum_{e_{j+1}} \pi\left(e_{j+1} \mid e_{j}\right) V\left(z_{j+1}\right)^{1-\eta}\right]^{\frac{1-\frac{1}{\gamma}}{1-\eta}}\right\}^{\frac{1}{1-\frac{1}{\gamma}}}
$$

where $\ell_{j}$ and $c_{j}$ denote leisure and consumption at age $j$ respectively and the parameter $\theta$ represents the rate of time preference. Since lifespan is uncertain, the expected utility in future periods is weighted with the survival probability $s_{j+1}$. Productivity $e_{j}$ at each age $j$ is uncertain and depends on the productivity in the previous period. Consequently, $\pi\left(e_{j+1} \mid e_{j}\right)$ denotes the probability to experience productivity $e_{j+1}$ in the next period if the current productivity is $e_{j}$. The parameters $\gamma$ and $\eta$ define the intertemporal elasticity of substitution between consumption and leisure in different years and the degree of (relative) risk aversion, respectively. Note that for the special case $\eta=\frac{1}{\gamma}$ we are back at the traditional expected utility specification, see Epstein and Zin (1991, 266). The period utility function is defined by

$$
u\left(c_{j}, \ell_{j}\right)=\left[\left(c_{j}\right)^{1-\frac{1}{\rho}}+\alpha\left(\ell_{j}\right)^{1-\frac{1}{\rho}}\right]^{\frac{1}{1-\frac{1}{\rho}}}
$$

where $\rho$ denotes the intratemporal elasticity of substitution between consumption and leisure at each age $j$. Finally, the leisure preference parameter $\alpha$ is assumed to be age 
independent. The budget constraint is defined as follows:

$$
\mathrm{a}_{j+1}=\mathrm{a}_{j}(1+r)+w_{j}\left(1-\tau_{j}\right)+p_{j}-s_{j}^{R}-T\left(y_{j}, s_{j}^{R}\right)-\left(1+\tau^{c}\right) c_{j}+b_{j}
$$

with $a_{1}=a_{J+1}=0$ and $a_{j} \geq 0 \forall j$. In addition to interest income from savings $r a_{j}$, households receive gross labor income $w_{j}=\left(1-\ell_{j}\right) w e_{j}$ during their working period as well as public pensions $p_{j}$ during retirement. They contribute to or withdraw from tax-favored accounts $s_{j}^{R}$ and have to pay progressive income taxes $T\left(y_{j}, s_{j}^{R}\right)$ which depend on taxable gross income $y_{j}$ and changes in tax-favored accounts. Due to a contribution ceiling the average contribution rate for public pensions $\tau_{j}$ depends on income. Finally, the price of consumption goods includes consumption taxes $\tau^{c}$ and $b_{j}$ defines the accidental bequests received at age $j$.

Our model abstracts from annuity markets ${ }^{3}$. Consequently, private assets of all agents who died are aggregated and then distributed among all cohorts following an exogenous age- and productivity dependent distribution scheme $\Gamma_{k}\left(j, e_{j}\right)$, i.e.

$$
b_{j}=\Gamma_{k}\left(j, e_{j}\right) \sum_{j=2}^{J} \sum_{z_{j}}(1+r)\left[a_{j}\left(z_{j}\right)+a_{j}^{R}\left(z_{j}\right)\left(1-\tau^{b}\right)\right] \xi\left(z_{j}\right)\left(1-s_{j}\right) N_{j-1}
$$

where $k \in\{u, p\}$. The age distribution of bequest is computed in the initial steady state where we assume that the heirs always receive the assets of the generation which was 25 years older. Within a generation we distinguish a uniform distribution $\Gamma_{u}\left(j, e_{j}\right)$ across different productivity types and a distribution $\Gamma_{p}\left(j, e_{j}\right)$ which is proportional to the current productivity level $e_{j}$. Inheritances from tax-favored accounts might be due to a specific inheritance $\operatorname{tax} \tau^{b}$.

Assets $\mathrm{a}_{j}^{R}$ in the tax-favored accounts accumulate according to

$$
\mathrm{a}_{j+1}^{R}=\mathrm{a}_{j}^{R}(1+r)+s_{j}^{R} \quad \text { with } \quad a_{1}^{R}=a_{J+1}^{R}=0 .
$$

In principle, assets could be withdrawn from the accounts before retirement (i.e. $s_{j}^{R}<$ $\left.0, j<j_{R}\right)$. However, preliminary withdrawal might be due to a penalty, which reduces the liquidity of tax-favored accounts compared to ordinary assets significantly.

In our model we assume that contributions to public pensions are exempted from tax while the benefits are fully taxed. Consequently, taxable gross income $y_{j}$ in $(3)$ is computed from gross labor income net of pension contributions, capital income (net of a saving allowance $d^{s}$ ) and (after retirement) public pensions net of a fixed work related allowance $d:$

$$
y_{j}=w_{j}\left(1-\tau_{j}\right)+\max \left[\mathrm{a}_{j} r-d^{s} ; 0\right]+p_{j}-d .
$$

\footnotetext{
${ }^{3}$ This is an important deviation from Riester accounts in Germany.
} 
Tax payments $T\left(y_{j}, s_{j}^{R}\right)$ depend on gross tax payments T05 $\left(y_{j}\right)$ net of saving subsidies. The latter consist of the tax savings from contributions to tax-favored accounts or (for low income households) a fixed, age-dependent bonus payment ("Zulage") $Z u l_{j}$, i.e.

$$
T\left(y_{j}, s_{j}^{R}\right)= \begin{cases}\mathrm{T} 05\left(y_{j}\right)-\max \left[\mathrm{T} 05\left(y_{j}\right)-\mathrm{T} 05\left(y_{j}-\min \left[s_{j}^{R}, \hat{s}\right]\right) ; Z u l_{j}\right] & \text { if } s_{j}^{R} \geq 0, \\ \operatorname{T} 05\left(y_{j}-[1-\phi] s_{j}^{R}\right)-\phi s_{j}^{R} & \text { if } s_{j}^{R}<0, j<j_{R}, \\ \operatorname{T} 05\left(y_{j}-s_{j}^{R}\right) & \text { if } s_{j}^{R}<0, j \geq j_{R} .\end{cases}
$$

As already explained, contributions to tax-favored accounts could only be deducted up to a limit which amounts to $\hat{s}$. Early withdrawals from tax-favored accounts might be subject to a penalty which amounts to $\phi$ percent of the withdrawal. The remaining fraction has to be fully taxed. According to (7) tax savings depend on individual contributions to tax-favored accounts $s_{j}^{R}$ and the marginal tax rate. For low income households the direct bonus payment might be higher. The latter is defined as a a hump-shaped agedependent transfer scheme $t r_{j}$ over the household life-cycle which is computed based on the final German bonus scheme ${ }^{4}$. Full bonus payments are only received if savings exceed a fixed share $\kappa$ of individual gross labor income $w_{j}$. In order to omit that bonuses exceed savings in tax-favored accounts, we restrict the maximum bonus payment to 95 percent of savings ${ }^{5}$. For contributions below the threshold, bonus payments are cut proportionally. Therefore, we have

$$
Z u l_{j}=\left\{\begin{array}{llr}
\min \left[t r_{j}, 0.95 s_{j}^{R}\right] & \text { if } & s_{j}^{R} \geq \kappa w_{j} \\
\min \left[\frac{s_{j}^{R}}{\kappa w_{j}} t r_{j}, 0.95 s_{j}^{R}\right] & \text { if } & 0 \leq s_{j}^{R}<\kappa w_{j}
\end{array}\right.
$$

\subsection{The production side}

The economy is populated by a large number of competitive firms, the sum of which we normalize to unity. Aggregate output $Y$ is produced using a Cobb-Douglas production technology, i.e.

$$
Y=\varrho K^{\varepsilon} L^{1-\varepsilon}
$$

where $K$ and $L$ are aggregate capital and labor, $\varepsilon$ is capital's share in production, and $\varrho$ is a technology parameter. Firms have to pay corporate taxes $T^{k}=\tau^{k}[Y-w L-\delta K]$ where the corporate tax rate $\tau^{k}$ of 15 percent is applied to the output net of labor costs $w L$ and depreciation $\delta K$.

\footnotetext{
${ }^{4}$ In and after 2008 a household will receive $185 €$ per child and $154 €$ per adult person.

${ }^{5}$ In Germany the government has specified specific minimum saving amounts which depend on the family structure.
} 
Firms will employ labor up to the point where the marginal product of labor equals labor costs. Similarly they will employ capital up to the point where the net marginal product of capital is equal to the interest rate:

$$
\begin{aligned}
& w=(1-\varepsilon) \varrho\left(\frac{K}{L}\right)^{\varepsilon} \\
& r=\left(1-\tau^{k}\right)\left[\varepsilon \varrho\left(\frac{L}{K}\right)^{1-\varepsilon}-\delta\right]
\end{aligned}
$$

\subsection{The government}

In each period the government issues new debt $\Delta B$ and collects taxes and social security contributions from households and firms in order to finance general government expenditures $G$ as well as interest payments on its debt:

$\Delta B+\sum_{j} \sum_{z_{j}}\left[T\left(y\left(z_{j}\right), s^{R}\left(z_{j}\right)\right)+\tau^{c} c\left(z_{j}\right)+\tau^{b}(1+r) a^{R}\left(z_{j}\right)\left(1-s_{j}\right) / s_{j}\right] \xi\left(z_{j}\right) N_{j}+T^{k}=G+r B$.

With respect to public debt, we assume initially that the government maintains an exogenously fixed debt to output ratio. General government expenditures $G$ consist of government purchases of goods and services which are fixed per capita. In order to balance the budget we adjust the consumption tax rate $\tau^{c}$.

In each year, the pension system pays old-age benefits and collects payroll contributions from wage income below the contribution ceiling which is fixed at two times the average income $\bar{w}$. Individual pension benefits $p_{j}$ of a retiree of age $j \geq j_{R}$ in a specific year are computed from the product of his earning points $e p_{j_{R}}$ the retiree has accumulated at retirement and the actual pension amount $(A P A)$ of the respective year:

$$
p_{j}=e p_{j_{R}} \times A P A
$$

The accumulated earning points depend on the relative income position $\min \left[w_{j} / \bar{w} ; 2\right]$ of the worker at working age $j<j_{R}$. Since the contribution ceiling is fixed at the double of average income, the maximum earning points that could be collected per year are 2 . Accumulated earning points at age $j$ are therefore

$$
e p_{j}=e p_{j-1}+\min \left[w_{j} / \bar{w} ; 2\right] .
$$

The budget of the pension system must be balanced in each period. Therefore, the general contribution rate $\tau$ has to be adjusted to fulfill the period budget constraint

$$
\sum_{j=j_{R}}^{J} \sum_{z_{j}} p\left(z_{j}\right) \xi\left(z_{j}\right) N_{j}=\tau \sum_{j=1}^{j_{R}-1} \sum_{z_{j}} \min \left[w\left(z_{j}\right) ; 2 \bar{w}\right] \xi\left(z_{j}\right) N_{j}
$$


The right hand side of equation (15) shows the individual contribution base. Households don't pay contribution on income above the contribution ceiling. Note that the general social security contribution rate $\tau$ which is calculated from (15) is not necessarily identical with the individual contribution rates in the budget constraint (3). The latter is given by

$$
\tau_{j}=\left\{\begin{array}{lll}
\tau & \text { if } & w_{j} \leq 2 \bar{w} \\
\tau 2 \bar{w} / w_{j} & \text { if } & w_{j}>2 \bar{w}
\end{array}\right.
$$

\section{Calibration}

In order to solve the model we have to specify the income process, preference and technology parameters and tax rates. This section presents our parameter choices and describes the initial equilibrium. ${ }^{6}$

\subsection{The income process}

We consider six productivity profiles across the life cycle. The four top profiles are directly taken from Fehr (1999) while the lowest profile from the previous study has been split up in order to improve the income distribution. When an agent enters the labor market (at age 20-24) he belongs to the lowest productivity level with a probability of 10 percent, to the second lowest again with 10 percent and to higher levels with 20 percent, respectively. After the initial period, agents change their productivity levels according to the following Markov transition matrix.

Table 1: Markov transition matrix

\begin{tabular}{|c|c|c|c|c|c|c|c|}
\hline & & \multicolumn{6}{|c|}{ Current productivity level } \\
\hline & & 1 & 2 & 3 & 4 & 5 & 6 \\
\hline & 1 & 0.40 & 0.24 & 0.17 & 0.09 & 0.05 & 0.04 \\
\hline & 2 & 0.17 & 0.35 & 0.33 & 0.09 & 0.04 & 0.02 \\
\hline Past & 3 & 0.08 & 0.13 & 0.41 & 0.24 & 0.10 & 0.04 \\
\hline productivity & 4 & 0.06 & 0.03 & 0.19 & 0.39 & 0.25 & 0.08 \\
\hline level & 5 & 0.04 & 0.02 & 0.10 & 0.22 & 0.41 & 0.22 \\
\hline & 6 & 0.04 & 0.03 & 0.05 & 0.06 & 0.20 & 0.63 \\
\hline
\end{tabular}

Source: Authors' own calculations from 1998/2003 SOEP data

\footnotetext{
${ }^{6}$ This section as well as subsection 4.1 follows closely Fehr and Habermann (2005).
} 
The Markov transition matrix is calculated as follows: First the primary earners in each household of the 1998 survey are ranked according to their gross income and then divided into six income classes. Then we rank and compute the respective income class of those persons who are still in the survey in 2003. Finally we calculate the above reported transition probabilities for each income class.

\subsection{Preferences, technology, demographics and bequest}

Table 2 reports the other important parameter values. Except the coefficient of relative risk aversion, all preference and technology parameters are taken from Auerbach and Kotlikoff $(1987,52 \mathrm{f}$.) as well as Fehr $(1999,57)$. Values between 1 and 5 for $\eta$ are typically perceived as reasonable in the literature, see Cecchetti et al. (2000, 792) for a discussion. The technology level is chosen in order to normalize labor income.

Table 2: Parameter values of the model

\begin{tabular}{lll}
\hline & Symbol & Value \\
\hline Utility function & & \\
time preference rate (p.a.) & $\theta$ & 0.01 \\
intertemporal elasticity of substitution & $\gamma$ & 0.5 \\
intratemporal elasticity of substitution & $\rho$ & 0.6 \\
coefficient of relative risk aversion & $\eta$ & 4.0 \\
leisure preference parameter & $\alpha$ & 1.5 \\
Production function & & \\
technology level & $\varrho$ & 1.48 \\
capital share in production & $\varepsilon$ & 0.30 \\
economic depreciation (p.a.) & $\delta$ & 0.05 \\
Policy parameters & & \\
corporate tax rate & $\tau^{k}$ & 15.0 \\
debt (in \% of GDP) & $B / Y$ & 60.0 \\
age of retirement $\left(\right.$ model age $\left.j_{R}=9\right)$ & & $60-64$ \\
replacement rate $\left(\left(j_{R}-1\right) \times A P A / \bar{w}^{n}\right)$ & & 0.6 \\
\hline
\end{tabular}

The actual pension amount $(A P A)$ in equation (13) is computed in order to yield a standard pension (i.e. where $e p_{j_{R}}=j_{R}-1$ ) which amounts to sixty percent of net average earnings $\bar{w}^{n}$.

The taxation of gross income (from labor, capital and pensions) is close to the current German income tax code and the marginal tax rate schedule introduced in 2005. Consequently, after the basic allowance of $7800 €$ the marginal tax rate rises linearly from 15 
to maximum of 42 percent when taxable income $y$ passes $52.000 €$. We assume that our individuals are married couples with a sole wage earner and apply the German income splitting method. For capital income there is a special allowance of $d^{s}=1800 €$ (per couple $)^{7}$.

Finally, with respect to the demographic parameters we compute average survival probabilities from Bomsdorf (2003) for the ages 20 to 99 as shown in Table A.1 in the appendix as well as the intergenerational bequest distribution.

\subsection{Initial equilibrium}

Table 3 reports the structure of the models initial equilibrium without tax-favored accounts and compares it with the respective figures in 2004 for Germany. All in all, the model represents the basic economic and fiscal structure of Germany quite well. Since the model is simulated as a closed economy, the interest rate is endogenous and the trade balance is zero. The key characteristics of the tax and pension system match the current German situation.

We have assumed in the benchmark equilibrium that inheritances are distributed uniformly within a generation (i.e. $\Gamma_{u}$ ). If we distribute inheritances proportional to the individual productivity, the inequality of the wealth distribution increases as well as aggregate savings. Consequently, the capital-output ratio is slightly higher at 3.3 while the interest rate slightly decreases to 2.7 percent. The structure of the tax and benefit system, however, is hardly affected by the distribution of inheritances.

Table 4 shows the distribution for net income and assets respectively. The percentage share of income (assets) is the share that accrues to subgroups of the population ranked by net income (assets). Our initial equilibrium replicates the German income distribution quite well, however, as usual, it underestimates the wealth inequality ${ }^{8}$. As already noted above, the proportional distribution of inheritances deteriorates the wealth distribution in the model. However, since rich (poor) households work less (more), the income distribution becomes more equal.

Finally, 10 percent of labor market entrants (i.e. the lowest income class) would like to borrow on the capital market in the initial equilibrium. For the following generations this fraction falls to $9,7,5$ and 2 percent, respectively.

This should suffice to explain our calibration and initial equilibrium. Next we turn to the

\footnotetext{
${ }^{7}$ In Germany this allowance is currently $3000 €$ for nominal interest income, but in our model we have no inflation and therefore we reduce this amount by about 40 percent.

${ }^{8}$ Heer and Trede $(2003,96)$ point out that this might be due to the neglected business ownership.
} 
Table 3: The initial equilibrium

\begin{tabular}{lrr}
\hline & Model & $\begin{array}{r}\text { Germany } \\
2004^{*}\end{array}$ \\
\hline Expenditures on GDP (\% of GDP) & & \\
private consumption & 63.8 & 59.1 \\
government purchases & 18.0 & 18.7 \\
gross investment & 18.2 & 17.3 \\
exports-imports & - & 4.9 \\
Government indicators & & \\
aggregate pension benefits (\% of GDP) & 13.1 & 12.2 \\
pension contribution rate (in \%) & 19.5 & 19.5 \\
tax revenues (in \% of GDP) & 19.9 & 20.0 \\
income tax & 7.3 & 6.7 \\
$\quad$ consumption tax & 10.8 & 10.5 \\
corporation tax & 1.8 & 1.8 \\
consumption tax rate (in \%) & 17.0 & - \\
& & \\
interest rate p.a. (in \%) & 3.0 & - \\
bequest (in \% of GDP) & 5.1 & $5.2^{a}$ \\
capital-output ratio & 3.2 & 3.0 \\
\hline
\end{tabular}

*Source: Institut der deutschen Wirtschaft (2005).

${ }^{a}$ Braun et al. (2002) for the year 2002.

Table 4: Income and wealth distribution

\begin{tabular}{|c|c|c|c|c|c|c|c|}
\hline & & \multicolumn{4}{|c|}{ Percentage share of income/assets } & \multirow{2}{*}{\multicolumn{2}{|c|}{$\begin{array}{l}\text { Gini } \\
\text { index }\end{array}$}} \\
\hline & & \multicolumn{2}{|c|}{ Lowest $10 \%$} & \multicolumn{2}{|c|}{ Highest $10 \%$} & & \\
\hline & & $\Gamma_{u}$ & $\Gamma_{p}$ & $\Gamma_{u}$ & $\Gamma_{p}$ & $\Gamma_{u}$ & $\Gamma_{p}$ \\
\hline \multirow{2}{*}{ Model } & net income & 3.2 & 3.2 & 22.7 & 22.4 & 0.293 & 0.290 \\
\hline & assets & 0.0 & 0.0 & 32.7 & 33.3 & 0.546 & 0.552 \\
\hline \multirow{2}{*}{ Germany* } & net income & \multirow{2}{*}{\multicolumn{2}{|c|}{$\begin{array}{l}3.1 \\
0.2\end{array}$}} & \multicolumn{2}{|c|}{23.9} & \multicolumn{2}{|c|}{0.299} \\
\hline & assets & & & \multicolumn{2}{|c|}{44.2} & \multicolumn{2}{|c|}{0.613} \\
\hline
\end{tabular}

* Source: DIW $(2005,202)$

policy reforms and their risk and efficiency implications. 


\section{Simulation results}

This section compares the macroeconomic and welfare consequences of the introduction of tax-favored accounts. Before the numerical results of the simulations are presented, we first explain the computation of the welfare changes.

\subsection{Experimental design and social welfare}

The welfare criterion we use to assess this reform is ex-ante expected utility of an agent, before the productivity level is revealed (i.e. looking upon her life behind the Rawlsian veil of ignorance). For an agent who enters the labor market the expected utility is computed from

$$
V=\left[\sum_{i=1}^{6} \pi_{i} V_{i}^{1-\eta}\right]^{\frac{1}{1-\eta}}
$$

where $\pi_{1}=\pi_{2}=0.1$ and $\pi_{3}=\cdots=\pi_{6}=0.2$. From that point of view one has some desire for redistribution, which provides insurance for being born as a low-productivity type. Following Auerbach and Kotlikoff $(1987,87)$ we compute the proportional increase in consumption and leisure $(W)$ which would make an agent in the baseline scenario as well off as in the reform scenario. If the expected utility level after the reform is $\hat{V}$ and the expected utility level on the baseline path is $\bar{V}$, the necessary increase (decrease) in percent of initial resources is computed from

$$
W=\left[\left(\frac{\hat{V}}{\bar{V}}\right)-1\right] \times 100 .
$$

Consequently, a value of $W=1.0$ indicates that this agent would need one percent more resources in the baseline scenario to attain expected utility $\hat{V}$.

In order to asses the aggregate efficiency consequences, we introduce a Lump-Sum Redistribution Authority (LSRA) in the spirit of Auerbach and Kotlikoff (1987, 65f.) as well as Nishiyama and Smetters (2005) or Fehr and Habermann (2005). The LSRA pays a lump-sum transfer (or levies a lump-sum tax) to each living household in the first period of the transition to bring their expected utility level back to the level of the initial equilibrium. Since utility depends on age and state, these transfers (or taxes) have to be computed for every agent in period one. Note that transfers differ only between the states of the earning points $e p_{j}$ and asset holdings $a_{j}$ and $a_{j}^{R}$ but not between efficiencies for agents with the same $e p_{j}, a_{j}$ and $a_{j}^{R}$. That is because the reform is announced before the productivity shock in period 1 is revealed. Consequently, age- $j$ agents who already worked before the reform are compensated by the transfers $v_{1}\left(z_{j}, \bar{V}\left(z_{j}\right)\right)$, which guaranties 
for each individual at state $z_{j}$ the initial expected utility level $\bar{V}\left(z_{j}\right)$. On the other hand, those who enter the labor market in period $t$ of the transition receive a transfer $v_{1 t}\left(V^{*}\right)$ which guaranties them an expected utility level $V^{*}$. Note that the transfers $v_{1 t}$ may differ among future cohorts but the expected utility level $V^{*}$ is identical for all. The value of the latter is chosen by requiring that the present value of all LSRA transfers is zero:

$$
\sum_{j=2}^{J} \sum_{z_{j}} v_{1}\left(z_{j}, \bar{V}\left(z_{j}\right)\right) \xi\left(z_{j}\right) N_{j}+\sum_{t=1}^{\infty}\left[\Pi_{k=0}^{t}\left(1+r_{k}\right)^{-1}\right] v_{1 t}\left(V^{*}\right) N_{1}=0 .
$$

With $V^{*}>\bar{V}$ (i.e. $W>0$ ), all households in period one who have lived in the previous period would be as well off as before the reform and all current and future newborn households would be strictly better off. Hence, the new policy is Pareto improving after lump-sum redistributions. With $V^{*}<\bar{V}$ (i.e. $W<0$ ), the policy reform is Pareto inferior after lump-sum redistributions. In order to asses the overall efficiency of the reform we will report the value of $W$ after compensation in the following tables.

\subsection{The benchmark reform experiment}

In order to fix the economic intuition, we apply our model first to a stylized reform experiment which has been never implemented in practice. In this benchmark simulation we assume that it is possible to subtract an unlimited amount from the income tax and save it in the tax-favored accounts (i.e. $\hat{s}=\infty$ ). There are no bonus payments (i.e. $\kappa=\infty$ ) and no penalties for early withdrawal (i.e. $\phi=0.0$ ). In order to guarantee a complete taxation at the time of withdrawal we assume that the specific inheritance tax rate is equal to the aggregate marginal income tax rate (i.e. $\tau^{b}=0.17$ ). Table 5 reports the macroeconomic consequences of this benchmark reform.

Since current assets are equal to savings from the previous period, the capital stock is fixed in the reform period and we report the changes of the second period in the first line of Table 5. Right after the introduction of tax-favored accounts households shift their liquid assets and additional savings into these accounts in order to balance marginal tax rates over the life cycle and reduce their tax burden. Since many elderly and poor individuals have no incentive to accumulate in the new accounts and rich households will only balance their marginal tax rates, the initial share of IRAs in total assets only amounts to slightly more than one third. About $\left(\frac{6}{1.06 \times 34}=\right) 16.6$ percent of IRAs consist of new savings, the rest is diverted from the already existing ordinary savings accounts. The IRA savings decrease aggregate income tax revenues as well as private consumption. Consequently, in order to balance the budget the consumption tax rate has to increase by 9.8 percentage points initially. Labor supply and employment increases due to the reduced marginal tax 
Table 5: Macroeconomic effects of tax-favored accounts in the benchmark*

\begin{tabular}{|c|c|c|c|c|c|c|}
\hline Period & 2005-09 & 2015-19 & $2025-29$ & 2035-39 & $2045-49$ & $\infty$ \\
\hline Capital stock & $6.0^{a}$ & 10.6 & 16.5 & 19.4 & 20.8 & 21.9 \\
\hline IRA share ${ }^{b}$ & $34^{a}$ & 59 & 83 & 93 & 95 & 96 \\
\hline Employment & 2.8 & 1.3 & 0.9 & 0.7 & 0.6 & 0.5 \\
\hline Consumption & -2.8 & -0.1 & 2.0 & 3.1 & 3.5 & 3.9 \\
\hline GDP & 2.0 & 4.0 & 5.4 & 6.0 & 6.3 & 6.5 \\
\hline Wage & -0.8 & 2.7 & 4.4 & 5.2 & 5.6 & 6.0 \\
\hline Interest rate p.a. ${ }^{c}$ & 0.1 & -0.4 & -0.7 & -0.8 & -0.9 & -0.9 \\
\hline Bequest & $1.3^{a}$ & 2.3 & 6.2 & 9.9 & 11.3 & 12.2 \\
\hline Consumption $\operatorname{tax}^{c}$ & 9.8 & 4.7 & 1.4 & -0.3 & -0.9 & -1.1 \\
\hline
\end{tabular}

${ }^{*}$ Changes are reported in percentage over initial equilibrium.

${ }^{a}$ Period 2010-2014. ${ }^{b}$ In percent of aggregate assets. ${ }^{c}$ Changes in percentage points.

burden on labor income, while wages have to decrease slightly in order to balance the labor market.

During the transition, the rising capital stock increases bequests and induces higher wages while the interest rate falls slightly. Consequently, aggregate consumption rises and consumption tax rates decrease even below the original level. In the long run, the aggregate capital stock increases by almost 22 percentage points and the consumption tax rate is reduced by more than one percentage point. The share of tax-favored assets in total assets (IRA share) increases steadily since younger households tend to save heavily in the new accounts. On first sight it might be surprising that in the long run not all savings are accumulated in the tax-favored accounts. However, those individuals who expect a high tax rate in retirement but face a lower marginal tax rate while working will save predominantly in ordinary accounts. In addition, poor households might be indifferent since their asset returns are below the specific savings allowance.

Next we consider the welfare changes for specific cohorts computed from equation (17) as well as the aggregate efficiency consequences of the benchmark reform in Figure $1^{9}$. Not surprisingly, the initial consumption tax increase especially hurts the elderly households, since they don't benefit from the income tax deductions. The welfare losses for the oldest generations amounts to more than four percent of their remaining resources. Welfare losses decrease with falling age since younger households can take advantage of tax deductions, experience higher wages and face lower consumption taxes. Those who enter the labor

\footnotetext{
${ }^{9}$ Note that we report the average welfare change for each cohort since we have to distinguish agents living in the reform year according to their current state.
} 
market in the reform period (i.e. year of birth is 1985) still face a welfare loss due to the reform, but younger generations will gain up to 2.5 percent of their resources.

Figure 1: Welfare effects of tax-favored accounts (benchmark case)

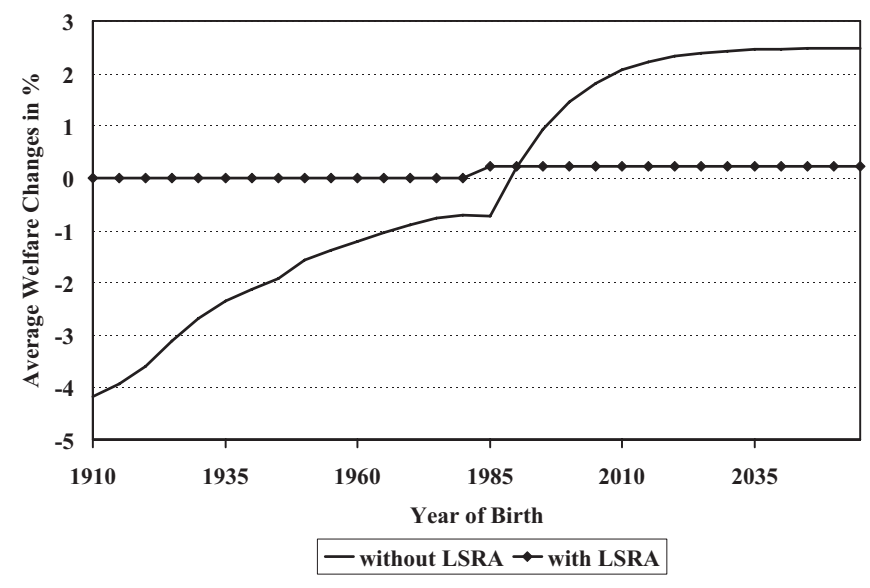

Figure 1 also shows that the considered benchmark reform would yield a slight Paretoimprovement. If all current households are compensated by LSRA transfers as described above, young and future households could still experience a welfare increase which amounts to 0.22 percent of initial resources. The aggregate efficiency gain is due to the induced changes in tax distortions and insurance properties of the tax system. As Nishiyama and Smetters (2005) have already shown, a reform towards consumption taxation will reduce tax distortions but also deteriorate the insurance properties of the tax system. In order to improve the economic intuition, Table 6 reports some sensitivity calculations for the aggregate efficiency effects of the considered benchmark reform. If we eliminate the taxation of inheritances, the aggregate efficiency gain increases from 0.22 percent to 0.37 percent. On first sight this is counterintuitive since the inheritance tax is a lump-sum tax so that its elimination increases tax distortions. However, uniformly distributed bequests serve as a insurance device against income shocks. Consequently, the elimination of inheritance taxes improves the insurance properties which in turn dominates the increased tax distortions. When bequests are distributed proportionally, they can't serve as an insurance device. Consequently, since the positive insurance effects from the higher bequests are missing in the left column, the reform yields an aggregate efficiency loss. If inheritance taxation is eliminated now, the aggregate efficiency losses rise due to the increased tax distortions.

Of course, the (negative) insurance effects of the reform are eliminated if we simulate the reform with risk neutral agents. Consequently, aggregate efficiency rises significantly in the right part of Table 6 . With the same reasoning, aggregate efficiency decreases, if 
Table 6: Aggregate efficiency effects: Sensitivity analysis

\begin{tabular}{lrrrr}
\hline$\gamma$ & 0.5 & 0.5 & 0.5 & 0.25 \\
$\eta$ & 4.0 & 4.0 & 0.0 & 0.0 \\
$\Gamma$ & $\Gamma_{p}$ & $\Gamma_{u}$ & $\Gamma_{u}$ & $\Gamma_{u}$ \\
\hline$\tau^{b}=0.17$ & -0.05 & $\mathbf{0 . 2 2}$ & 1.14 & 0.98 \\
$\tau^{b}=0.00$ & -0.46 & 0.37 & 1.04 & 0.78 \\
\hline
\end{tabular}

we simulate the reform now without inheritance taxation. Finally, a lower intertemporal elasticity of substitution will also slightly dampen the reduction in tax distortions. Consequently, aggregate efficiency in the last column is lower than in the previous one.

\subsection{Policy reforms with endogenous debt}

Due to the variation of the endogenous consumption tax rate, the benchmark reform of the previous section induced a significant intergenerational redistribution. In order to dampen the latter, this subsection considers an alternative reform strategy which implements a constant consumption tax rate to balance the intertemporal budget constraint of the government. Periodical shortfalls or surpluses of tax revenues are balanced by adjustments of public debt.

In the first simulation introduces tax-favored accounts as in the previous subsection. This form of retirement saving taxation is also called front-loaded. Since the exemption of savings returns from tax is only one form of expenditure taxation, the second simulation introduces back-loaded IRAs where contributions are not tax deductible but withdrawals are tax free. Since we abstract from any restrictions on contributions and withdrawals, back-loaded IRAs are identical to a preannounced elimination of interest taxation (i.e. $d^{s}=\infty$ in equation (6)). Table 7 compares the long run impact of the two considered reforms and the respective efficiency consequences.

With front-loaded IRAs, the consumption tax rate has to be increased immediately by 2.6 percentage points right after the reform. Since this does not suffice to balance the revenue shortfalls, the government accumulates public debt which rises (from 60 per cent of GDP initially) up to 146 percent of GDP. As before, tax-favored accounts reduce the tax burden of middle-aged and elderly. Consequently, they save more and transfer more to their descendants. However, due to the increase in public debt capital accumulation is much weaker than before. Of course, the latter dampens the long run growth in consumption, output and wages. Note that the aggregate efficiency gains are now higher than in 
Table 7: Long-run effects of debt-financed IRAs*

\begin{tabular}{|c|c|c|c|}
\hline & \multirow{2}{*}{$\begin{array}{l}\text { Benchmark } \\
\text { reform }\end{array}$} & \multicolumn{2}{|c|}{ Debt-financed IRAs } \\
\hline & & Front-loaded & Back-loaded \\
\hline Capital stock & 21.9 & 9.9 & 6.0 \\
\hline Aggegate Savings & 21.9 & 32.3 & 5.2 \\
\hline Aggregate IRA share ${ }^{a}$ & 96 & 92 & 100 \\
\hline Employment & 0.5 & 0.1 & 0.5 \\
\hline Consumption & 3.9 & 1.8 & 1.6 \\
\hline GDP & 6.5 & 2.9 & 2.1 \\
\hline Wage & 6.0 & 2.8 & 1.6 \\
\hline Interest rate p.a. ${ }^{b}$ & -0.9 & -0.5 & -0.3 \\
\hline Bequest & 12.2 & 31.4 & 5.6 \\
\hline Consumption $\operatorname{tax}^{b}$ & -1.1 & 2.6 & 1.1 \\
\hline Efficiency gains ${ }^{c}$ & 0.22 & 0.34 & 0.13 \\
\hline
\end{tabular}

${ }^{*}$ Changes are reported in percentage over initial equilibrium.

${ }^{a}$ In percent of aggregate assets. ${ }^{b}$ Changes in percentage points.

${ }^{c}$ In percent of remaining resources.

the benchmark since intertemporal distortions from the fluctuating consumption tax are eliminated.

In contrast, a preannounced elimination of capital income taxation would increase the consumption tax rate only by 1.1 percentage point throughout the transition. Since individuals can't reduce their tax burdens on labor income with higher savings ${ }^{10}$, the capital accumulation is weaker than before. On the other hand, back-loaded IRAs allow to reduce public debt in the long run slightly to 59.5 percent of GDP. Consequently, aggegate savings increase less than the capital stock. Finally, due to the still high marginal tax burdens on labor income aggregate efficiency gains are dampened compared to the previous simulation.

Figure 2 compares the intergenerational welfare consequences of the two reform strategies with the benchmark case. Note first that now the losses of the elderly are much smaller than before. In the case of debt-financed front-loaded IRAs, pension benefits increase initially due to higher labor supply. Consequently, higher consumption taxes now reduce mainly the welfare of young retirees by about 0.5 percent of their resources. Younger generations benefit from higher inheritances, wages and better tax arbitrage opportunities. The introduction of debt-financed back-loaded IRAs reduces the welfare of elderly only

\footnotetext{
${ }^{10}$ Of course, if we would allow them to accumulate individual debt, progressive income taxes would not necessarily increase savings, see Ragan (1994).
} 
slightly since they benefit directly from the elimination of capital income taxes. The latter almost balances the loss from the increased consumption tax rate. Young and future generations benefit again due to higher wages.

Figure 2: Welfare effects of tax-favored accounts (debt-financing)

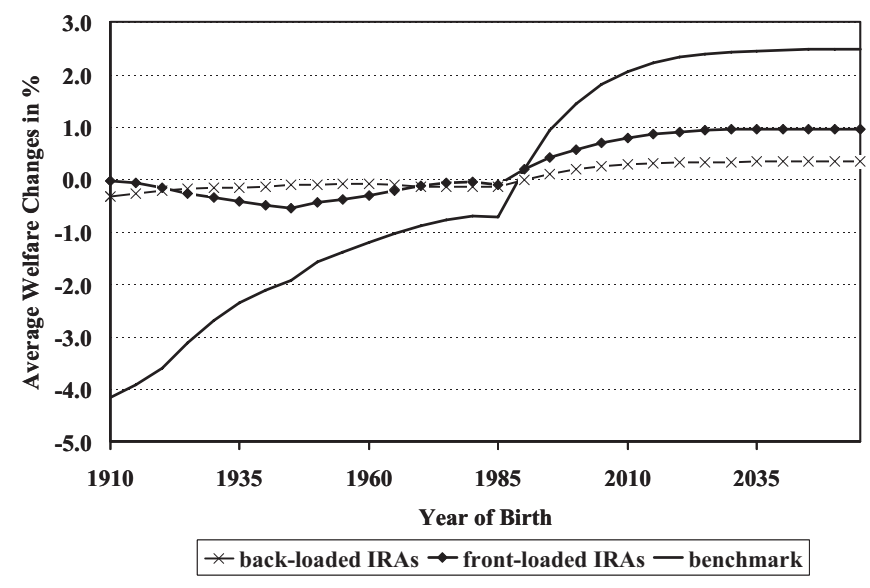

Since both reforms considered above eliminate the taxation of capital income with a constant consumption tax rate, the literature often highlights the equivalence of these two forms of expenditure taxation, see Meade $(1978,153)$. In the present model, the difference between front-loaded and back-loaded IRAs in terms of their macroeconomic and welfare consequences is mainly due to the progressive income tax system and the differences in the timing and the pattern of tax payments. If we assume a proportional income tax, a small open economy and phase-in the introduction of both reforms (i.e. only the young in each period are allowed to open an IRA) we obtain the equivalence result cited in the literature. However, in practice, back-loaded and front-loaded IRAs are not equivalent due to these restrictions.

Summing up this subsection we conclude that a deficit-financed introduction of frontloaded IRAs would only modestly hurt currently living generations and increase the growth and efficiency gains compared to the benchmark simulation. However, since the debt level rises enormously, such a reform is not viable in practice. Consequently, in the following subsection we return to the constant debt assumption of the benchmark and consider more realistic institutional arrangements which limit revenue shortfalls and the intergenerational redistribution. 


\subsection{Penalties, contribution ceilings and bonus payments}

As already explained above, the withdrawal from the accounts is usually restricted in various ways. For example in Germany, savers have to pay back their tax savings on balances which are withdrawn before age 60 and have to convert their assets into annuities after retirement. Other countries such as the US apply an early withdrawal penalty which severely lowers the liquidity of the tax-favored accounts. In addition, in order to limit revenue shortfalls, countries allow tax deduction only up to a specific contribution ceiling. Finally, some special special arrangements such as bonus payments in Germany might be provided for low income households. In the following simulations we always assume the most extreme case, where early withdrawal is not possible at all (i.e. $\phi=1.0$ ). Table 8 then compares saving incentives in the form of unlimited or limited tax deductions with other systems were direct bonus payments are applied.

The first simulation only introduces withdrawal restrictions but keeps the benchmark values for the remaining parameters. When the liquidity of the tax-favored accounts during the working phase is eliminated, people will save less in these accounts. Consequently, compared to the benchmark case in Table 5 the capital accumulation is now dampened, and the IRA share is significantly lower. On the other hand, employment and wages still rise by 0.8 and 4.5 percent, respectively, in the long run and the consumption tax rate increases initially by 7.8 percentage points. Due to the reduced initial increase of the consumption tax rate, the intergenerational redistribution is dampened. The oldest generations now lose less then 4 percent of their remaining lifetime resources and the future generations gain less than 2 percent. On the other hand, aggregate efficiency gains increase slightly from 0.22 to 0.30 percent. Of course, liquidity restrictions reduce the efficiency of the resource allocation. However, they also restrict the shift from the progressive income tax to the consumption tax. The latter improves the insurance properties of the tax system and, consequently, aggregate efficiency rises ${ }^{11}$.

Next we consider the introduction of contribution limits. The ceiling of $2100 €$ in Germany amounts to roughly 8 percent of average gross earnings. Contribution limits significantly reduce the tax arbitrage opportunities for rich households. Their marginal tax rate for labor income either remains constant (if they are in the top tax bracket) or declines only slightly compared to the previous simulation. In addition, if they save more than the contribution ceiling, their effective marginal tax rate on savings is not affected by the reform. Consequently, the long-run IRA savings only amount to 40 percent of aggregate

\footnotetext{
${ }^{11}$ If we introduce withdrawal restrictions when individuals are risk neutral, aggregate efficiency decreases significantly.
} 
Table 8: Tax-favored accounts with withdrawal restrictions $(\phi=1.0)^{*}$

\begin{tabular}{|c|c|c|c|c|c|c|}
\hline \multirow[b]{2}{*}{ Variable } & \multicolumn{3}{|c|}{$\begin{array}{l}\text { Tax deductions } \\
\qquad(\kappa=\infty)\end{array}$} & \multicolumn{2}{|c|}{$\begin{array}{l}\text { Bonus payments } \\
\quad(\hat{s}=0.0)\end{array}$} & \multirow{2}{*}{$\begin{array}{c}\text { Mixed } \\
\kappa=0.04 \\
\hat{s}=0.08 \bar{w}\end{array}$} \\
\hline & $\hat{s}=\infty$ & $\hat{s}=0.08 \bar{w}$ & $\hat{s}=0.16 \bar{w}$ & $\kappa=0.04$ & $\kappa=0.08$ & \\
\hline \multicolumn{7}{|c|}{ Capital stock } \\
\hline $2010-15$ & 4.6 & 1.0 & 1.5 & 0.6 & 0.6 & 1.0 \\
\hline 2015-19 & 7.9 & 1.8 & 2.9 & 1.2 & 1.1 & 1.9 \\
\hline $2025-29$ & 12.5 & 3.2 & 5.4 & 2.2 & 2.1 & 3.4 \\
\hline$\infty$ & 16.7 & 5.6 & 9.6 & 4.1 & 3.5 & 6.2 \\
\hline \multicolumn{7}{|l|}{ IRA share ${ }^{a}$} \\
\hline $2010-15$ & 27 & 8 & 11 & 7 & 8 & 8 \\
\hline 2015-19 & 44 & 15 & 22 & 14 & 15 & 16 \\
\hline $2025-29$ & 63 & 27 & 38 & 25 & 26 & 28 \\
\hline$\infty$ & 70 & 40 & 53 & 36 & 35 & 42 \\
\hline \multicolumn{7}{|c|}{ Employment } \\
\hline 2005-09 & 1.8 & 0.3 & 0.4 & -0.3 & -0.3 & 0.0 \\
\hline 2015-19 & 1.0 & 0.2 & 0.4 & -0.2 & -0.2 & 0.0 \\
\hline $2025-29$ & 1.0 & 0.2 & 0.4 & -0.2 & -0.2 & 0.0 \\
\hline$\infty$ & 0.8 & 0.2 & 0.2 & -0.2 & -0.2 & -0.1 \\
\hline \multicolumn{7}{|l|}{ Wages } \\
\hline 2005-09 & -0.5 & -0.1 & -0.1 & 0.1 & 0.1 & 0.0 \\
\hline 2015-19 & 2.0 & 0.5 & 0.8 & 0.4 & 0.4 & 0.6 \\
\hline $2025-29$ & 3.3 & 0.9 & 1.5 & 0.7 & 0.7 & 1.0 \\
\hline$\infty$ & 4.5 & 1.6 & 2.7 & 1.3 & 1.1 & 1.9 \\
\hline \multicolumn{7}{|c|}{ Consumption $\operatorname{tax}^{b}$} \\
\hline 2005-09 & 7.8 & 1.8 & 2.8 & 1.6 & 1.4 & 2.2 \\
\hline 2015-19 & 3.3 & 1.4 & 2.3 & 1.3 & 1.0 & 1.8 \\
\hline $2025-29$ & 0.7 & 1.0 & 1.5 & 0.9 & 0.6 & 1.4 \\
\hline$\infty$ & -0.7 & -0.2 & -0.3 & 0.0 & -0.3 & 0.1 \\
\hline Efficiency $^{c}$ & 0.30 & -0.09 & -0.11 & 0.03 & 0.12 & -0.01 \\
\hline
\end{tabular}

${ }^{*}$ Changes are reported in percentage over initial equilibrium. ${ }^{a}$ In percent of aggregate assets.

${ }^{b}$ In percentage points. ${ }^{c}$ In percent of initial resources.

savings and the capital stock increases by 5.6 percent $^{12}$. The consumption tax has to be increased by 1.8 percentage points initially and falls in the long run slightly below the original level. Since marginal income tax rates hardly change for many rich households but consumption taxes increase initially, efficiency gains fall significantly compared to the previous simulation. The considered reform now yields an aggregate efficiency loss of about 0.1 percent of aggregate resources.

A doubling of the contribution limit has a significant effect on capital accumulation and

${ }^{12}$ Note that İmrohoroğlu, et al. $(1998,759)$ find a similar modest long-run increase in the capital stock. 
GDP. Aggregate efficiency, however, is hardly affected since (positive) tax incentive and (negative) insurance effects balance on aggregate.

While contribution ceilings mainly affect the saving decision of wealthy individuals, bonus payments are an attractive incentive for low income households. In Germany, the agedependent bonus scheme roughly amounts to the tax savings of an average income household if he contributes 4 percent of his income to the tax-favored account. As reported in the forth column of Table 8, with our specific calibration bonus payments are cheaper in terms of forgone tax revenues than contribution limits but also induce lower growth effects for capital stock and employment. Aggregate efficiency gains are slightly positive, since bonus payments can be viewed as an insurance device for low income households. Increasing the required contribution for full bonuses from 4 to 8 percent of individual income reduces the incentive to accumulate capital. This in turn leads to a lower consumption taxes during transition. The IRA share, on the other hand, is hardly affected since households shift resources from their ordinary savings accounts into tax-favored accounts. Nevertheless, aggregate efficiency slightly increases to 0.12 percent of aggregate resources due to lower consumption taxes.

Finally, we simulate a mixed incentive system which resembles the German setting described above. Depending on the individual advantage of the respective subsidy, households either receive bonus payments or tax deductions up to the contribution ceiling. Since this mixture combines saving incentives both for low and top income households, the induced growth effects for the capital stock are higher than in the respective reforms were either limited tax deductions or bonus payments are applied. Aggregate efficiency is almost zero in this case.

Next we consider in Figure 3 the intergenerational welfare consequences of tax deductions with contribution limits $(\hat{s}=0.08 \bar{w})$ and bonus payments $(\kappa=0.04)$. Compared to the benchmark in Figure 1, the intergenerational redistribution in now very modest. The oldest generations lose roughly one percent of their remaining resources, while future generations gain less than one percent. Due to the strongest initial consumption tax increase, the mixed reform reduces welfare of elderly the most. Since employment rises in the case of contribution ceilings while it falls with bonus payments, pensions increase slightly in the former case while they fall in the latter. Consequently, elderly are slightly better of with contribution ceilings than with bonus payments. In the long run, the mixed system generates the strongest wage growth so that future generations are better off compared to the two other scenarios.

In order to shed more light on the difference between tax deductions and bonus payments, we compare in Figure 4 the welfare consequences for different productivity types of the 
Figure 3: Welfare effects of tax-favored accounts (tax deductions vs. bonuses)

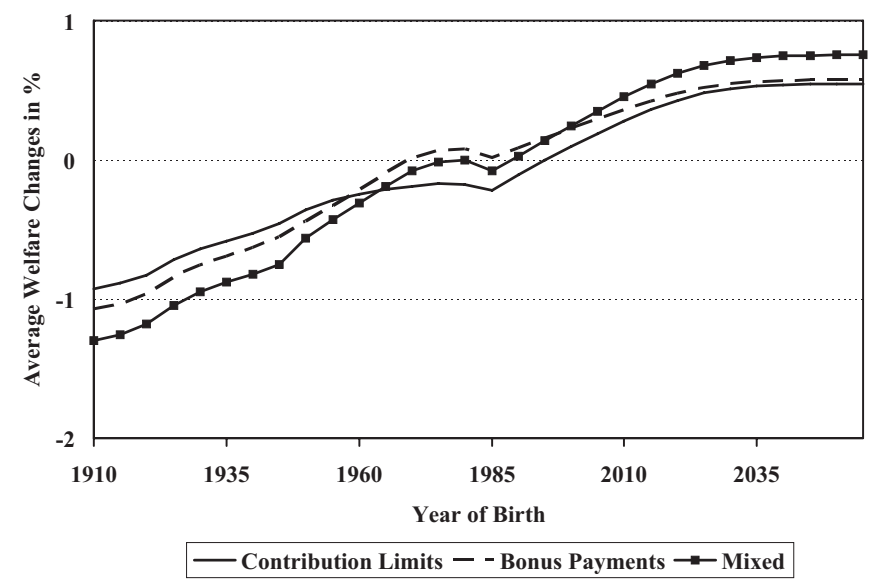

generation that enters the labor market in the reform period (i.e. year of birth 1985 in Figure 3). As one would expect, low productivity individuals benefit much stronger from bonus payments than from tax deductions. For top productivity households the difference is negligible, due to the risk of becoming a low productivity type in the future.

Figure 4: Short-run welfare effects (tax deductions vs. bonuses)

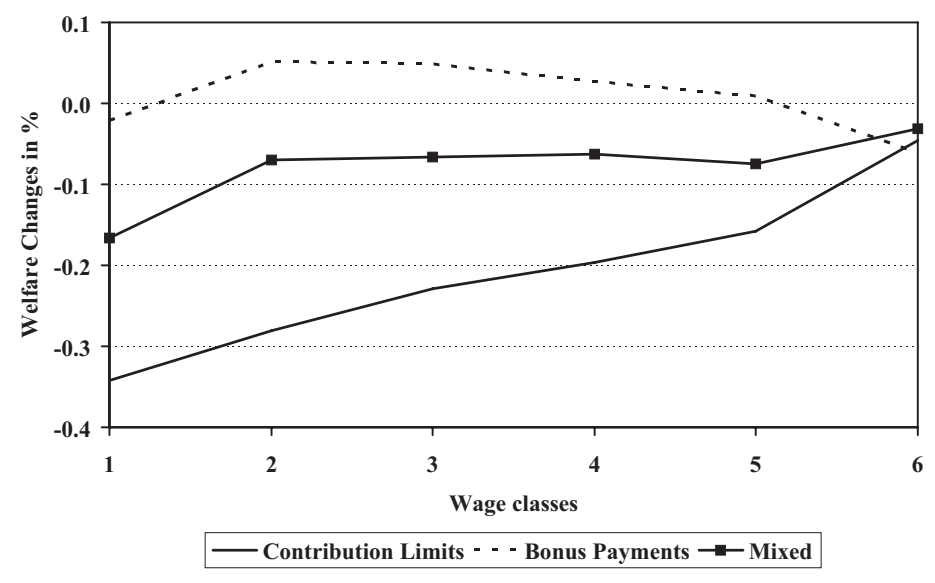

In the long run, the relative advantage of the different subsidy instrument changes. As Figure 5 shows, now the mixed system is better for low productivity types due to the higher wages.

Concluding this subsection our simulations therefore indicate that although bonus payments are an efficient means for low income households even the latter would opt for a mixed system in the long run. 
Figure 5: Long-run welfare effects (tax deductions vs. bonuses)

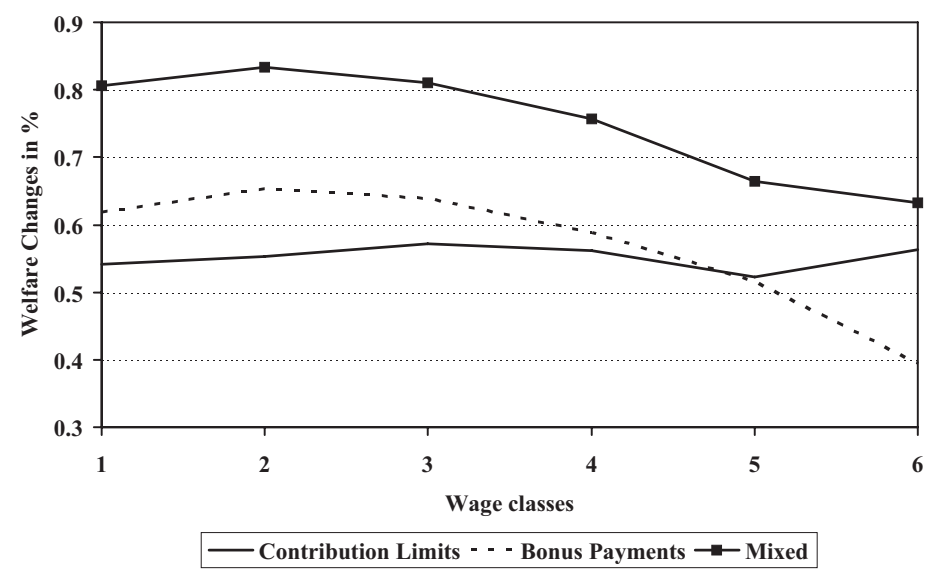

\section{Conclusion}

The present paper develops a general equilibrium model with idiosyncratic labor income risk in order to analyze the introduction of tax-favored individual retirement accounts. We find that the currently implemented reforms will have a significant impact on capital accumulation in the long run, but only yield very minor aggregate efficiency gains. The main beneficiaries are future generations while current middle-aged and elderly are hurt by the reform. The latter is due to the fact that existing cohorts mainly have to bear the burden from higher consumption taxes while young and future generations benefit from lower tax burdens and higher future wages.

We also show that withdrawal penalties only have a minor impact on the macroeconomy. While tax deductions are mainly beneficial for top income households, low income households can be effectively subsidized with direct bonus payments. In the long run, however, even low income households prefer a mixture of direct bonuses and tax deductions since the latter increases wages stronger.

Of course, the present framework could be extended in various other directions. In future work we plan to extend our model in order to analyze the efficiency of additional subsidy instruments for retirement savings, mandatory savings accounts and the required annuitization of retirement income. 


\section{Appendix}

Survival probabilities and bequest distribution

\begin{tabular}{lll}
\hline Age & $\begin{array}{l}\text { Survival } \\
\text { probability }\end{array}$ & $\begin{array}{l}\text { Bequest } \\
\text { share }\end{array}$ \\
\hline $20-24$ & 1.000 & 0.045 \\
$25-29$ & 0.997 & 0.052 \\
$30-34$ & 0.997 & 0.088 \\
$35-39$ & 0.995 & 0.144 \\
$40-44$ & 0.991 & 0.180 \\
$45-49$ & 0.986 & 0.191 \\
$50-54$ & 0.978 & 0.170 \\
$55-59$ & 0.966 & 0.130 \\
$60-64$ & 0.947 & 0.000 \\
$65-69$ & 0.913 & 0.000 \\
$70-74$ & 0.862 & 0.000 \\
$75-79$ & 0.777 & 0.000 \\
$80-84$ & 0.646 & 0.000 \\
$85-89$ & 0.470 & 0.000 \\
$90-94$ & 0.298 & 0.000 \\
$95-99$ & 0.167 & 0.000 \\
\hline
\end{tabular}

\section{Computational Method}

The state of a household is determined by $z_{j}=\left(j, e p_{j}, a_{j}^{R}, a_{j}, e_{j}\right) \in \mathcal{J} \times \mathcal{P} \times \mathcal{A}^{R} \times \mathcal{A} \times \mathcal{E}$ where $\mathcal{J}=\{1, \ldots, J\}, \mathcal{P}=\left\{e p^{1}, \ldots, e p^{n_{P}}\right\}, \mathcal{A}^{R}=\left\{a^{R, 1}, \ldots, a^{R, n_{R}}\right\}, \mathcal{A}=\left\{a^{1}, \ldots, a^{n_{A}}\right\}$ and $\mathcal{E}=\left\{e^{1}, \ldots, e^{n_{E}}\right\}$ are discrete sets. In this paper we use $n_{J}=16, n_{p}=5, n_{R}=$ $12, n_{A}=12$ and $n_{E}=6$. For all these possible states $z_{j}$ we compute the optimal decision of households from (1).

Since $u\left(c_{j}, \ell_{j}\right)$ is not differentiable in every $\left(c_{j}, \ell_{j}\right)$ and $V\left(z_{j+1}\right)$ is only known in a discrete set of points $z_{j+1} \in\{j+1\} \times \mathcal{P} \times \mathcal{A}^{R} \times \mathcal{A} \times \mathcal{E}$, this maximization problem can not be solved analytically. Therefore we have to use the following numerical maximization and interpolation algorithms to compute households optimal decision:

1. Compute (1) in age $J$ for all possible $z_{J}$. Notice that $V\left(z_{J+1}\right)=0$ and households are not allowed to work anymore. Hence, in the optimum households should consume everything they have.

2. For $j=J-1, \ldots, 1$ : 
Find (1) for all possible $z_{j}$ by using Powell's algorithm (Press et. al. (2001, 406ff.), Acton $(1990,464 f f)$.$) . Since this algorithm requires a continuous function, we have$ to interpolate $V\left(z_{j+1}\right)$. Having computed the data $V\left(z_{j+1}\right)$ for all $z_{j+1} \in\{j+$ $1\} \times \mathcal{P} \times \mathcal{A}^{R} \times \mathcal{A} \times \mathcal{E}$ in the last step, we can now find functions $\operatorname{sp}_{(j+1), k}$ for each productivity level $e^{k} \in \mathcal{E}$ which satisfy the interpolation conditions

$$
s p_{j+1, k}\left(z_{(j+1), k}\right)=V\left(z_{(j+1), k}\right) \quad, \quad z_{(j+1), k}=\left(j+1, e p_{j+1}^{l}, a_{j+1}^{R, m}, a_{j+1}^{n}, e_{j+1}^{k}\right)
$$

for all $l=1, \ldots, n_{P}, m=1, \ldots, n_{R}$ and $n=1, \ldots, n_{A}$. In this paper we use multidimensional cubic spline interpolation, i.e. $s_{j, k}: \mathcal{S}_{3} \times \mathcal{S}_{3} \times \mathcal{S}_{3} \rightarrow \mathbb{R}$, whereas $\mathcal{S}_{3}$ is the space of all one-dimensional, twice continuously differentiable, piecewise third-order polynomial functions and $\mathcal{S}_{3} \times \mathcal{S}_{3} \times \mathcal{S}_{3}$ its tensor product (cf. Judd $(1998,225 f f)$.$) . Further information is available upon request, see Habermann and$ Kindermann (2006). The multidimensional cubic spline interpolation allows a reduction of $n_{P}, n_{R}$ and $n_{A}$ to only a few points with the same accuracy as multilinear interpolation.

Having computed the data $V\left(z_{j}\right)$ for all $z_{j}$ we can now approach like İmrohoroğlu et. al. (1995).

\section{References}

Acton, F.S. (1990): Numerical Methods that work, The Mathematical Association of America, Washington.

Auerbach, A.J. and L.J. Kotlikoff (1987): Dynamic fiscal policy, Cambridge University Press, Cambridge.

Bomsdorf, E. (2003): Sterbewahrscheinlichkeiten der Periodensterbetafeln für die Jahre 2000 bis 2100, Eul Verlag, Köln.

Bernheim, D. (2002): Taxation and Saving, in: A. Auerbach und M. Feldstein (Hrsg.), Handbook of Public Economics, Vol. 3, Amsterdam, 1173-1250.

Braun, R. u.a. (2002): Erben in Deutschland - Volumen, Psychologie und gesamtwirtschaftliche Auswirkungen, Deutsches Institut für Altersvorsorge, Köln.

Cecchetti, S.G., P.S. Lam and N.C. Mark (2000): Asset pricing with distorted beliefs: Are equity returns too good to be true? American Economic Review 90, 787-805. 
Conesa, J.C. and D. Krueger (1999): Social security reform with heterogeneous agents, Review of Economic Dynamics 2, 757-795.

De Nardi, M. S. İmrohoroğlu and T. J. Sargent (1999): Projected U.S. demographics and social security, Review of Economic Dynamics 2, 575-615.

De Nardi, M., S. İmrohoroğlu und T. J. Sargent (2001): Saving and Pension Reform in General Equilibrium Models, Oxford Review of Economic Policy 17(1), 20-39.

Deutsches Institut für Wirtschaftsforschung (DIW) (2005): Verteilung von Vermögen und Einkommen in Deutschland, Wochenbericht des DIW Berlin Nr. 11, 199-207.

Epstein, L.G. and S.E. Zin (1991): Substitution, risk aversion, and the temporal behavior of consumption and asset returns: An empirical analysis, Journal of Political Economy 99, 263-286.

Engen, E.M., W.G. Gale und J.K. Scholz (1994): Do Saving Incentives Work? Brookings Papers on Economic Activity 1, 85-180.

Fehr, H. (1999): Welfare effects of dynamic tax reforms, Mohr Siebeck, Tuebingen.

Fehr, H. and C. Habermann (2005): Risk sharing and efficiency implications of progressive pension arrangements, CESifo Working Paper No. 1568, Munich.

Habermann, C. and F. Kindermann (2006): Multidimensional spline interpolation: Theory and applications, mimeo, University of Wuerzburg.

Heer, B. and M. Trede (2003): Efficiency and distribution effects of a revenue-neutral income tax reform, Journal of Macroeconomics 25, 87-107.

Huang, H., S. İmrohoroğlu and T. J. Sargent (1997): Two computations to fund social security, Macroeconomic Dynamics 1, 7-44.

Institut der Deutschen Wirtschaft (2005): Deutschland in Zahlen, Köln.

İmrohoroğlu, A., S. İmrohoroğlu and D.H. Joines (1995): A life cycle analysis of social security, Economic Theory 6 (1), 83-114.

İmrohoroğlu, A., S. İmrohoroğlu and D.H. Joines (1998): The effect of tax-favored retirement accounts on capital accumulation, American Economic Review 88 (4), S.749768.

Judd, K.L. (1998): Numerical Methods in Economics, The MIT Press, Cambridge. 
Meade, J.E. (1978): The Structure and Reform of Direct Taxation, London: George Allan and Unwin.

Nishiyama, S. and K. Smetters (2005): Consumption taxes and economic efficiency with idiosyncratic wage shocks, Journal of Political Economy 113, 1088-1115.

Press, W.H., S.A. Teukolsky, W.T. Vetterling and B.P. Flannery (2001): Numerical Recipes in Fortran 77, Volume 1 of Fortran Numerical Recipes, Cambridge University Press, Cambridge.

OECD (2005): Tax-Favoured Retirement Saving, OECD Economic Studies No. 39, 2004/2, Paris.

Ragan, C. (1994): Progressive income taxes and the substitution effect of RRSPs, Canadian Journal of Economics 27, 43-57. 